\title{
Severe asthma in childhood
}

\author{
Fernando Maria de Benedictis \\ From 71st Congress of the Italian Society of Pediatrics. Joint National Meeting SIP, SIMGePeD, Study Group \\ on Pediatric Ultrasoun, SUP Study Group on Hypertension \\ Rome, Italy. 4-6 June 2015
}

In the majority of cases, asthma in children may be easily controlled by available drugs. However, a substantial subset exists who remain "difficult to treat". The burden of the disease for these children is enormous in terms of quality of life, social problems, resources expenditure and mortality.

Over the last 15 years, several international committees have proposed different definitions for severe asthma. In order to revise such definition and provide guidance about the management of patients with severe asthma, a jointed ERS/ATS Task Force has recently published a document addressed to the specialists in respiratory medicine and allergy [1].

It is defined "severe", asthma which requires treatment with guidelines suggested medications for GINA steps 4-5 asthma (high dose ICS and LABA or leukotriene modifier/theophylline) for the previous year or systemic CS foro $50 \%$ of the previous year to prevent it from becoming "uncontrolled" or which remains "uncontrolled" despite this therapy.

Uncontrolled asthma defined as at least one of the following: 1) Poor symptom control: ACQ consistently $>1.5$, ACT $<20$ (or "not well controlled" by NAEPP/GINA guidelines); 2) Frequent severe exacerbations: two or more bursts of systemic CS ( $>3$ days each) in the previous year; 3) Serious exacerbations: at least one hospitalisation, ICU stay or mechanical ventilation in the previous year; 4) Airflow limitation: after appropriate bronchodilator withhold FEV1 $<80 \%$ predicted (in the face of reduced FEV1/FVC defined as less than the lower limit of normal); 5) Controlled asthma that worsens on tapering of these high doses of ICS or systemic CS (or additional biologics).

Inherent in the definition of severe asthma is the exclusion of individuals who present with "difficult asthma" in whom appropriate diagnosis and/or

Correspondence: pediatria@fmdebenedictis.it

Dipartimento Materno-Infantile, Azienda Ospedaliero-Universitaria, Ospedali Riuniti, Ancona, Italy and take full advantage of:

- Convenient online submission

- Thorough peer review

- No space constraints or color figure charges

- Immediate publication on acceptance

- Inclusion in PubMed, CAS, Scopus and Google Scholar

- Research which is freely available for redistribution Submit your manuscript at
www.biomedcentral.com/submit C BioMed Central 